\title{
The Group Level of Aspiration and External Social Pressures ${ }^{1}$
}

\author{
Alvin Zander and Cyrus Ulberg \\ Research Center for Group Dynamics, The University of Michigan, \\ Ann Arbor, Michigan 48106
}

\begin{abstract}
It has been observed in research on the group level of aspiration that social pressures arising outside a group influence the aspiration level members chose; pressures toward improvement in group performance appear to be more effective than those toward no improvement. It is possible, however, that these results are an artifact in some degree of the preference members commonly reveal for more difficult group tasks. In the present experiment the difficulty of an external standard pressed upon a croup and the success or failure of the group on its task are made to be indenendent events. When the members' usual preference for harder aspiration ivels is ruled out, a harder external standard is no more influential than an easier one. Regardless of its difficulty, an external standard is less influential if it is inappropriate to the prior performance of the group or to a member's strength of desire for group success; in such an instance a member's aspiration for his group is determined by the preference of his teammates. Members of groups with greater desire for group suecess set harder aspiration levels and perform better than those with less desire for group success.
\end{abstract}

Conditions that affect the nature of a group's goals have been studied in recent experiments by placing a group in a situation of the type that is commonly used for investigating individual levels of aspiration. In these studies a set of persons work on a task that requires cooperative effort, repeat the task a number of times, and obtain a group score after each trial. Before the next trial members are asked to select the score they expect their unit will be able to earn in the future. This is the group's aspiration for the group or more simply, the group's aspiration level.

Results indicate that the location of a group aspiration is a function of both the perceived probability of success and the potential satisfaction from such success, just as is the placement of an individual's

\footnotetext{
${ }^{1}$ This research was financed by a contract with the Air Force Office of Scientific Research.
} 
own aspiration. Also, the strength of the members' group-oriented motivation to do well, called the desire for group success, affects the level of aspiration members select in much the same way as an individual's need for achievement affects his personal aspiration (Zander, 1968, 1971).

Several specific conditions, known to determine where a group places its aspiration level, are of more than passing interest because they apparently can cause groups to develop an unreasonable level of aspiration, too high or too low in the light of the group's prior record of performance, and the members as a result use an inappropriate criterion for evaluating their group's output. Failure to achieve an extremely difficult level, moreover, apparently fosters procedures within the group that generate future failures (Zander \& Medow, 1963; Zander \& Newcomb, 1967; Zander, Forward, \& Albert, 1969). This seeming willingness of decision makers to select an unreasonable group aspiration under particular conditions, even though this choice creates problems for the group, was a prime stimulus for the experiment described in this report.

The conditions of special interest are: (a) The success (or failure) of the group on its task, and (b) the difficulty of an external standard, a source of social pressure acting on a group to change its level of performance. Each of these matters, (a) and (b), have an obvious and well-established part in determining a group's aspiration level, but little is known about how they interact and how they modify one another. There is reason to believe that this interaction deserves closer scrutiny. How does group success or failure influence members' responses to external social pressures?

(a) In group aspiration setting, when there is no external pressure at work on a group, members typically shift their group's aspiration level from trial to trial in accord with the rule: succeed, raise; fail, lower. It is sometimes observed, however, that this rule is not strictly followed as members often raise the aspiration level after a success more than they lower it after a failure. As a result, the mean level of aspiration tends to be higher after a success than after a failure; yet, the discrepancy between the last level of performance and the future level of aspiration (the $d$ score) tends to be larger after a failure than after a success. This latter discrepancy means that a group usually sets a more difficult goal, in the light of its prior level of performance, after a failure than after a success. The reason that members set a harder goal after a failure than after a success, because they thereafter anticipate more satisfaction if their group succeeds or less dissatisfaction if it fails, is discussed fully elsewhere (Zander, 1971).

(b) When a group is constrained to set a level of aspiration for each trial while receiving external pressures directed either toward improve- 
ment or no improvement in performance, the members are strongly inclined to shift their group's aspiration up or down to conform with the level proposed in the external standard (Zander \& Medow, 1963; Zander, Medow, \& Efron, 1965; Forward \& Zander, in press). External pressures to reduce the group's output often are less influential than pressures to increase it, suggesting that there is a greater readiness to conform to pressures in support of a difficult standard than to those in support of an easy standard.

The precise effects of external pressures come into question, however, when we note further in the studies just mentioned that influence attempts directed toward a better performance trial after trial, regardless of any improvement in the group's score, typically generate more failure than successes, and the aspiration is not regularly lowered after each failure; whereas repeated pressures toward a lower output regardless of the group's score generate more successes than failures, and the level of aspiration is usually raised (a small amount) after each success. To some unknown degree, then, a more difficult external standard may be more influential in determining a group's aspiration level because members ordinarily dislike to lower their group's aspiration after a failure, and an easier standard may be less influential because members prefer to raise the group's aspiration after a success.

Clearly, the members' responses to their group's success or failure and their responses to external social pressures are each likely to affect the other in such a way that the contribution of one may simply be an artifact of the other. What is wanted is an experimental procedure in which the occurrence of success or failure is largely independent of the level advocated by the external pressure, so that one is not consistently accompanied by the other and the separate contribution of each can be independently observed. Such a procedure is employed in the present study.

The experimental design, described more fully below, allowed an equal probability of each of four treatments to occur for each group: A group success followed by a hard external standard, a group success followed by an easy standard, a group failure followed by a hard standard, and a group failure followed by an easy standard. In order to create these treatments, each group freely chose its group level of aspiration before each trial. Prior to this choice members were told the group's (alleged) score on its most recent attempt; this score was one of a preplanned and programmed set of values so located in relation to the immediately prior level of aspiration that each group had equal numbers of successes and failures and these on the average were similar in size. The subjects were then given a standard for their next attempt 
originating from a credible source outside the group. Each external standard was also programmed, in reference to the prior level of aspiration, so that hard and easy standards were equal in frequency and equal in their average discrepancy from that past aspiration.

The mean absolute discrepancy between the external standard given to participants and the group aspiration chosen immediately thereafter was taken to be an indicator that the external standard had had an influence upon the level of aspiration; the smaller the discrepancy between standard and aspiration (i.e., the greater the congruency), the greater the likelihood that the standard had influenced the members' choice of aspiration. The Hypothesis $(a)$ is: Congruence between members' aspirations for their group and a standard of performance pressed on the group is larger when this standard is difficult than when it is easy. The experimental procedure makes it possible to examine whether congruence with harder external standards is a manifestation of the standard's influence or merely a preference for harder aspirations.

The desire for group success is a group level analog of the individual need for achievement. It is known that members with more of this desire, compared to those with less, are more eager to have their group attain a success that is highly satisfying, more often place their group's aspiration at a location that promises the greatest probability of satisfaction from success, and work harder in order to ensure their attainment of success (Zander \& Medow, 1965; Forward, 1969). Hypothesis (b): Members with greater desire for group success will select aspirations that have greater congruence with hard standards than with easy ones.

It has been observed in prior research that central members of a group, compared to peripheral members, develop a stronger desire for group success (Medow \& Zander, 1965; Zander \& Forward, 1968). Hypothesis $(c)$ : Central members, in contrast to peripheral members, will select aspirations that have greater congruence with hard standards than with easy ones.

\section{METHOD}

The subjects were 96 boys in the eleventh grade of a suburban high school who were invited to take part in a test of ability-in-teamwork. In order to legitimize the reporting of external standards, each boy was appointed a member of a four-man team and led to believe that the score his team earned, together with the scores of other teams, would determine how well his school performed in competition with a number of nearby schools. A conference room in the school building was used as a laboratory. When subjects arrived they were seated at a circular table and separated from one another by wooden screens. 


\section{Desire for Group Success}

Groups were treated in a way that was intended to generate either a high desire for group success (high DGS) or a low desire for group success (low DGS) among members. Contrasting strengths of this desire were created by two separate but supplementary methods: (a) Selection of subjects for a given group on the basis of the score each student received on a pretest, and (b) remarks to the members in each group on the meaning of a given pretest score and the importance of the task facing the group.

One week before the experiment began a questionnaire was administered to 193 boys in the eleventh grade. This instrument contained a number of questions that asked about the respondent's interest in group achievement. An example: "If a group I belong to is given an important task to do, I like to see them try to do the very best they can on it." Groups in the high DGS treatment were composed of boys who received higher scores on this test and units in the low DGS treatment were composed of boys who received lower scores. Because there is as yet no evidence that a given score on this instrument is a valid measure of the desire for group success, even though the questions on their face appear to be reasonable indicators of what they are supposed to measure, the experimenter also instructed each group on the meaning of the scores on this test.

In his recital he reminded the boys of the pretest questionnaire and told them it measured whether a person was more interested in working with others or preferred to work alone. A high score, he added, meant that a person had a strong interest in teamwork and team achievement. A low score showed that a person was more interested in individual endeavor and in getting things done on his own. In the high DGS condition the experimenter remarked that the scores of the boys in this team were unusually high. He spent a few moments in addition commenting favorably on the importance of the ability to be tested in the group today and the interest the task arouses in those who work on it. In the low DGS condition he said that the scores in this group were unusually low, added that the importance of the ability being tested today was as yet unknown and apologized for the rather dull nature of the task their group would have to work on.

\section{Experimental Task}

The participants were told that their unit would take an examination called a "team information processing test." It required them to count the number of holes in electronic data processing cards as rapidly and 
accurately as they could. At the beginning of each trial each member (except for the central member to be discussed below) received two cards with holes punched in three separate fields, each field covering ten columns on each card. No two of the fields on any of the cards were alike in the number or positions of these holes. Each field was labeled with a letter, A, B, or C, corresponding to designations given each of the three team members. On each trial a subject counted the number of holes in his field, wrote this total on the card, and passed it along to the member on his left. When all three fields were counted on a card it was placed in a box at the center of the table.

They were informed that the basic score for their group was the number of seconds consumed in completing the task, including the time for summation of the separate field totals by the fourth member. Accuracy was stressed by the additional rule that three seconds would be added to their group's total time for every error in counting.

The participants were trained in all aspects of the task during two practice trials; the second of these was timed and this time was reported to the subjects. Eight test trials were then run. During these, it was evident, the participants worked hard and were deeply interested in having their group do well.

\section{Central and Peripheral Social Positions}

The counting of holes was done by three members who were assumed to be in peripheral positions. The fourth had a more central role and his function was described, for all to hear, as the "chief coordinator" of the group. While explaining the group's task, the experimenter made it clear that the person in position $\mathrm{D}$ had the responsibility to see that the cards were not unduly delayed at any position, to add the field totals together for a card total, and to check the accuracy of the other members whenever he had time to do so.

\section{Aspirations for the Group}

Prior to each trial, team members were given ballots on which they were to state the score they "expect the team will be able to achieve" on the next trial. This is a member's aspiration for his group. The four ballots were collected and all were read aloud, the highest and lowest among these four values were discarded and the average of the middle two computed. This average was reported to the group as the group's aspiration level. It was posted on the blackboard for each trial in sequence, as was the group's score and the external standard proposed for the group. The reason given participants for asking them to establish these aspirations was that it helps a team to improve if it sets a goal 
before each new attempt on a task and if it thus realizes how well the group is performing.

\section{Feedback on Performance}

At the conclusion of each trial the experimenter announced the team's "time." This was not the exact time taken by the group (although its actual speed and accuracy were measured and recorded) but instead was a preplanned and programmed score so that all groups might have exactly the same number of successes and failures. The program for a given group, randomly determined, indicated how much was to be added to the level of aspiration for the trial just finished (thus creating a failure to achieve the aspiration level), or how much was to be subtracted from the level of aspiration (thus creating a success). Every group had four successes and four failures randomly scattered throughout the eight trials; the average amount of success as well as the average amount of failure was precisely the same for every group.

\section{External Standard of Group Performance}

The subjects understood that their school was competing against other schools and that their team's score contributed toward the total score earned by the school. Before each trial, accordingly, a team was told what score would be a "fair share" for it to attain on the next trial in order that their school have a good chance to beat other schools. This is designated as the external standard. It was important that this expectation from outside the group be perceived by members as a response to the unique performance of their team and not as an arbitrary or inflexible norm. To invoke such a perception, the participants were informed that a panel of local teachers together with the experimenter had used a computer to develop a complex table of standards. With the help of values in this table, the experimenter stated, it was possible to tell what a given group should earn on the next trial, taking into account its recent scores, recent aspirations, and the tendency of groups to improve with practice. Thus, each group standard for each trial was to be seen by subjects as a custom-made standard for that group in the light of its history up to that moment.

On half of its trials a group received a hard external standard and in the other half an easy standard. A hard standard was 4-8 sec more difficult than the given group's aspiration level on its prior trial and an easy standard was 4-8 sec easier. Whether the standard for a trial was to be hard or easy, and by how much, was predetermined and programmed in such a way that each group was exposed to the same average discrepancy between prior aspiration and external standard. 
In order to preserve the credibility of these standards, it was necessary to follow any occurrence of two failures in a row by a hard external standard and to follow any occurrence of two successes in a row by an easy standard. This procedure slightly reduced the independence between difficulty of standard and success or failure of the group. Even so, all four potential treatments occurred with a useful and reasonably similar frequence.

\section{Post Experimental Questionnaire}

After the eighth test trial the subjects were asked to complete a brief questionnaire asking about their reactions to the test thus far. Examples of these questions are noted in Table 3 . When they had finished the form, the boys were informed the session was over and the purposes and procedures of the experiment were fully explained. Their questions were answered in detail, they were told what they might reveal to curious classmates, and they were asked to remain silent about other features of the test for the next few days.

\section{RESULTS}

\section{Selection of Group Aspiration Levels}

Considering first the average amount of shift in members' aspiration for the group from trial to trial, the change was toward a more difficult level after a success (mean 4.44), and likewise after a failure (mean 1.43) ; thus, there was a typical raise in aspiration level following a success, but an atypical increase following a failure. Also, the mean shift in aspiration level was upward, after being exposed to a hard external standard (mean 4.68), as well as to an easy standard (mean 1.22). The net result is that the level of aspiration generally shifted upward from trial to trial in all conditions, more so after a success than after a failure, just as has often been found in prior studies.

It was predicted in Hypothesis (a) that congruence between the external standard and members' aspirations for the group will be stronger when the standard is difficult than when it is easy. This hypothesis was supported: When the standard was easy the mean discrepancy between external standard and aspiration for group was 8.16, and when the standard was hard, the mean discrepancy was $4.62(p<.001)$. The difference between these two means was largely generated by a very large discrepancy when an easy external standard followed a group success.

The tendency for members to shift the group aspiration toward harder levels (noted above), suggests that the congruence just described may 
in good part be the result of a preference for harder goals rather than an indication of a stronger influence by a harder standard. It was necessary therefore to adjust the measure of congruence by ruling out any effects that might be due to the preference for selecting harder aspiration levels trial by trial.

In order to normalize the shifts in aspiration, the mean shift in aspiration for the group by all subjects was subtracted from the aspiration level proposed by each subject within each trial; in effect the mean shift in group aspiration over all trials (both successful and unsuccessful) was made to equal zero. When this correction was applied, the hard standard generated no more congruence than the easy one-the mean discrepancy for each was about 5.70. It is clear then that the support for Hypothesis (a), mentioned above, was mainly an artifact of the greater preference for harder aspiration levels. Support for the hypothesis cannot be taken to mean that hard and easy external standards differed in their influence upon the aspirations members favored for their group.

How does the effect of a harder or easier external standard compare to the effect of a group success or failure in determining the mean shift in group aspiration? Such a comparison can be made by observing the mean shift in aspiration level within each of the four experimental conditions while the control on the preference for harder aspirations, as was done above, is again applied. The results are displayed in Fig. 1.

It is evident that a greater upward shift in aspiration occurs after a success when a hard standard is proposed than when an easy one is offered, and a larger downward shift occurs after a failure when an

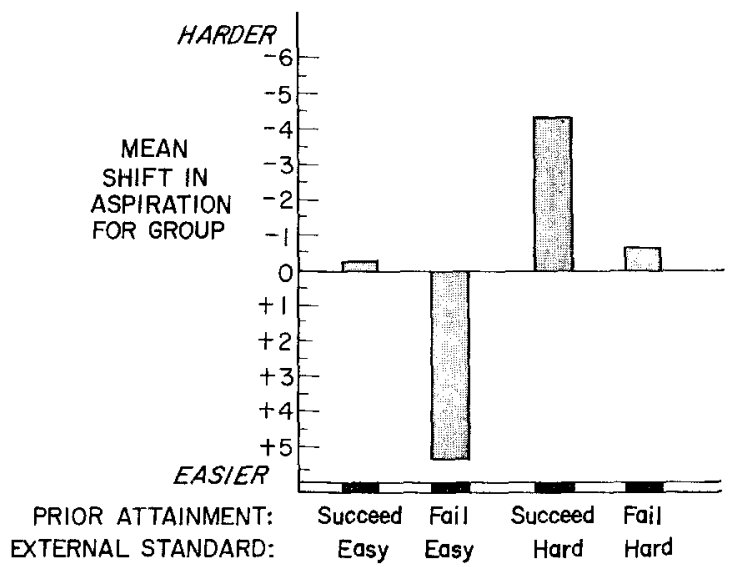

FIG. 1. Shifts in aspiration for group after controlling the preference for harder levels. 
easy standard is provided than when a hard one occurs. The pressures arising from these separate events are clearly additive when in the same direction; they virtually cancel the effects of one another when in opposing directions. Under the conditions employed, a reaction to an easy or difficult external standard is similar to the reaction to a success or failure.

Returning to the degree of congruence between external standard and group aspiration, the results in Fig. 1 suggest that it is useful to look more closely at the sources of this congruence by eliminating not only the upward drift of aspiration levels (as was done above) but by controlling the differential shifts in aspiration level generated by either the group's success or failure. To do this, the mean shift upward by all subjects after a success was subtracted from each subject's aspiration for the group after a success, and the mean shift downward by all subjects after a failure was added to each subject's aspiration for the group after a failure. The amount of congruence between external standard and aspiration was then examined in each of the four treatments. The results are summarized in the upper part of Table 1. They reveal a source of influence that had not been apparent in previous studies.

In the table the discrepancy is greatest (congruence is least) in the two cases when the level of the external standard is (presumably) different from what the members expected, i.e., when an easy standard follows a success or a hard standard follows a failure. In these two dissonant conditions, it appears, the members' aspiration choice is based on information other than that implied in the external standard. The discrepancy is least (congruence is greatest) when the level of the

TABLE 1

Mean Discrepancy Between Members' Aspirations for Group, Externat Standard, and Group's Prior Aspiration Level

\begin{tabular}{lcc}
\hline & $\begin{array}{c}\text { Easy } \\
\text { standard }\end{array}$ & $\begin{array}{c}\text { Hard } \\
\text { standard }\end{array}$ \\
\hline $\begin{array}{c}\text { Discrepancy: aspiration for } \\
\text { group and external standard }\end{array}$ & & \\
Success & 6.11 & 5.09 \\
Failure & 4.91 & 5.50 \\
Discrepancy: aspiration for group & $F=3.85, p<.05$ \\
and group's prior aspiration & & 5.35 \\
Success & 4.44 & 4.21 \\
Failure & 5.82 & \\
& $F=11.94, p<.01$ \\
\hline
\end{tabular}


standard suits what the members probably expected, i.e., when a hard standard follows a success or an easy standard follows a failure. Seemingly, then, the attention members give to an external standard depends in part upon whether it is, cognitively, what is perceived to be an appropriately directed pressure on the group, after the group has experienced either a success or a failure. These results, it should be emphasized, are not at all a product of the preferred reactions to success or failure since the latter have been wholly eliminated; they can reasonably be conceived as evidence of the influence created by the external standard.

If a member is indeed inclined to ignore the external standard when the latter is perceived to be unfitting, it is likely that he is uncertain where to place his group's aspiration level. A possible source of relief from this uncertainty is to turn to the views held by teammates. If he accepts others' beliefs in such an instance, one should find that the discrepancy between own aspiration for the group and the group's prior level of aspiration is smaller where the congruence between own aspiration and the external standard is smaller, i.e., where the external standard is apparently perceived to be unsuitable. The results in the lower part of Table 1 indicate that this latter discrepancy is smaller in just those instances. It appears then that a participant is less likely to be influenced by external standards, and more likely to be influenced by statements of his peers, when the level of the extemal standard is less appropriate to the group's immediate past success or failure.

\section{The Desire for Group Success}

The results discussed thus far were the same in both high DGS and low DGS groups. Participants in the high DGS condition behaved differently from those in the low DGS condition in other ways, however, that suggest the former were more interested in attaining a satisfactory group success. The high DGS groups worked faster than the low DGS groups, consuming 86.17 and 93.74 sec, respectively $(p<.001)$; the highs did better after a success (mean $84.64 \mathrm{sec}$ ) than after a failure (mean 87.69 sec), whereas the lows took about $94 \mathrm{sec}$ regardless of whether they had just succeeded or failed $(F=9.85, p<.001)$. Members in the high DGS condition were also more accurate than those in the low DGS condition $(p<.05)$. Those in groups with stronger DGS furthermore gave responses on a number of questions, at the conclusion of the experiment, indicating that they were more favorable toward the task, toward working hard, and toward their own and their group's quality of performance, than were the participants with weaker DGS. These results are summarized in Table 3 . 
Groups in the high DGS condition, compared to those in the low DGS condition, set harder levels of aspiration $(p<.001)$, shifted their group aspirations upward to a greater degree trial by trial $(p<.05)$, and placed their aspiration a greater distance above the score just reported to their group, a discrepancy commonly denoted as the $d$ score $(p<$ .025). The high DGS condition, it is plain, invoked a stronger preference for harder tasks.

It was predicted in Hypothesis (b) that members with greater DGS will place their group aspirations in closer congruence to hard external standards than to easy ones. This hypothesis was supported $(p<.01)$, but the greater preference among members in the high DGS condition for more difficult aspirations, just noted, suggests that a hard standard may have had no more true influence than an easy one. Instead, the higher aspiration levels chosen by those in the high DGS condition may have deviated little from the high standards and deviated much from the lower standards simply because of the members' preference for higher aspirations. A correction was once more necessary. In this instance the average shift in group aspiration of all subjects was subtracted from each subject's aspiration after the group had been given a hard external standard and the average shift of all subjects was added to each subject's aspiration after the group had been given an easy standard. The discrepancy between the external standard and the members' aspiration for the group after these adjustments had been made is shown in Table 2 .

It is apparent that the participants are more attentive to an external standard that fits their general desires than they are to one that does not fit. Less attention is paid to the external standard when the group is

\section{TABLE 2}

Mean Discrepancy Between Members' Aspiration for Group and Externat Standard for Group

\begin{tabular}{ccc}
\hline & $\begin{array}{c}\text { Easy } \\
\text { standard }\end{array}$ & $\begin{array}{c}\text { Hard } \\
\text { standard }\end{array}$ \\
\hline $\begin{array}{c}\text { Control on aspiration shift due } \\
\text { to impact of external standard } \\
\text { High DGS }\end{array}$ & 7.57 & 5.81 \\
Low DGS & 6.77 & 7.52 \\
Control on aspiration shift due & $F=10.29, p<.01$ \\
to group success of failure & & \\
High DGS & 5.95 & 6.66 \\
Low DGS & 5.49 & 6.03 \\
& $F=6.41, p<.01$ \\
\hline
\end{tabular}


high in desire for group success and receives an easy standard or is low in that desire and receives a high standard. Again, an unsuitable standard is less influential than a suitable standard.

The lower part of Table 2 displays the congruence between external standard and group aspiration after the shifts following success have been removed and those following a failure have been added, as was done for the data in the upper part of Table 1. The findings are generally similar to those just described but somewhat weaker. They indicate that the effects due to DGS are not mainly manifestations of members' reactions to the group's success or failure.

\section{Central and Peripheral Positions}

The occupants of the central and peripheral positions were different in only one noteworthy respect. Those in a central position, more than those in a peripheral post, placed their aspirations for the group closer to the level of the external standard: The mean discrepancy between external standard and member's aspirations for the group was 5.08 for those in a central post, and 5.97 for those in a peripheral position $(p<.05)$. This result was consistent regardless of whether their group had succeeded or failed and regardless of the central or peripheral member's reaction to group success or failure. It had been predicted in Hypothesis (c) that central members would place their aspirations closer to harder external standards than would peripheral persons. This hypothesis was not supported. Central members on the whole reacted to events in the group just as their teammates did.

\section{History of Success or Failure}

The involvement of members in a group's task and the strength of their desire for the group to do well has been measured in previous experiments by the use of post-experimental questions similar to those listed in Table 3. Participants in groups with more successes than failures, compared to those in groups with more failures than successes, have typically responded to such questions in ways that indicate their greater interest in the group's success and their stronger willingness to extend themselves in behalf of the group (Zander \& Medow, 1963; Zander, Forward, \& Albert, 1969).

In the present experiment each group had the same number of successes and failures, although these occurred in different sequences, comparing one group with another. Some of the groups experienced several failures or several successes in a row and one or the other of such clusters could have been early or late in the set of trials. Because members in prior studies may have developed an image of their group as either skilled or 
TABLE 3

Attitudes Towaro Experimental Situation

History of attainment

\begin{tabular}{|c|c|c|c|c|c|c|c|}
\hline & & & & & & & \\
\hline & \multicolumn{3}{|c|}{ Desire for group success } & \multirow{2}{*}{$\begin{array}{l}\text { Succeed } \\
\text { and } \\
\text { fail } \\
\text { mixed } \\
\bar{X}\end{array}$} & \multirow{2}{*}{$\begin{array}{c}\text { Fail } \\
\text { early } \\
\text { succeed } \\
\text { late } \\
\bar{X}\end{array}$} & \multirow{2}{*}{$\begin{array}{c}\text { Succeed } \\
\text { early } \\
\text { fail } \\
\text { late } \\
\bar{X}\end{array}$} & \multirow[b]{2}{*}{$F$} \\
\hline & $\underset{\bar{X}}{\mathrm{High}}$ & $\begin{array}{l}\text { Low } \\
\bar{X}\end{array}$ & $F$ & & & & \\
\hline $\begin{array}{l}\text { Importance of } \\
\text { setting attain- } \\
\text { able goal }\end{array}$ & 11.60 & 10.02 & $6.18^{* *}$ & 11.71 & 9.65 & 9.45 & $5.85^{* *}$ \\
\hline $\begin{array}{l}\text { Was helpful to } \\
\text { set goal }\end{array}$ & 11.60 & 9.17 & $12.74^{* * * *}$ & 11.48 & 9.85 & 7.85 & $10.57^{* *}$ \\
\hline $\begin{array}{l}\text { Attention paid to } \\
\text { external } \\
\text { standards }\end{array}$ & 7.89 & 7.69 & 1.71 & 8.98 & 7.25 & 6.85 & $3.15^{*}$ \\
\hline $\begin{array}{l}\text { Importance of } \\
\text { school beating } \\
\text { other schools }\end{array}$ & 12.71 & 10.69 & $15.40^{* * * *}$ & 12.09 & 11.70 & 10.60 & 2.44 \\
\hline $\begin{array}{l}\text { Evaluation of } \\
\text { team's perfor- } \\
\text { mance }\end{array}$ & 10.63 & 8.73 & $15.31^{* * *}$ & 10.23 & 9.55 & 8.25 & $4.77^{* *}$ \\
\hline $\begin{array}{l}\text { Evaluation of } \\
\text { personal } \\
\text { performance }\end{array}$ & 9.81 & 8.35 & $11.37^{* * *}$ & 9.46 & 9.10 & 8.00 & $3.30^{*}$ \\
\hline
\end{tabular}

Note: Questions coded on 14-point scale.

${ }^{*} p<.05$.

${ }^{* *} p<.025$.

${ }^{* * *} p<.001$.

inept, due to the rather consistent success or failure of their unit when exposed to repeated easy or hard standards, we were curious whether clusters of successes or failures had an effect on the subjects' readiness to approach or to avoid the task of the group. We wondered, moreover, whether groups with no particular clumping of success or failure would thereupon have a stronger or weaker desire to approach the work of the group -in effect they have little evidence on which they can make a judgment about the group's most likely level of achievement.

Accordingly, the groups were divided into three types. The first contained those whose group successes and failures were rather evenly scattered throughout the series of trials, the second included those whose failures more often occurred in the first half of the trials and successes in the latter half, the third held those whose successes more often occurred in the first half of the trials and failures in the latter half. The mean 
responses on the post-experimental questionnaire for each of the three types are revealed in Table 3 .

It is notable that the subjects with the most scatter in their successes and failures were consistently more favorable toward, and involved in, the group's task and evaluated their group's performance more favorably. A clustering, either of successes or failures, generated less interest in the task and less favorable evaluations. The subjects who failed more often later in the series of trials had the least interest in approaching the group's work, suggesting a recency effect. Even those who succeeded more often toward the end, and who might well have interpreted their late successes as a sign of impovement in skill, apparently had their involvement in the group's activity tempered by the recall of the failures they had experienced in the first half of the experimental period. All in all, it appears that no reliable news about the quality of performance, because failures are as frequent as successes, is taken to be good news.

The clustering of success or failure did not affect the shifts in aspiration levels any more than did a single trial's experience of success or failure, nor did clustering affect the degree of congruence with the external standards.

\section{DISCUSSION}

A major purpose of this investigation was to examine the differential effect of hard or easy external standards upon the level of aspiration members select for their group when this standard and the group's success or failure are independent events. The most important results were not quite what had been expected. The difficulty of the external standard as such did not determine its ability to influence the aspiration choice, as was the case in previous research. Instead the standard's impact was apparently determined by its appropriateness to the member's desires. An external standard was given little attention by members if it was seen as pressing toward attainment of a level of performance that members presumably did not favor and was given considerable attention if it was directed toward a level of performance that was similar to the members' most likely aspiration choice. The member's preferred aspiration choice was deduced in each instance from an immediately prior group success or failure, or from the presumed strength of member's desire for group success. Plainly, the impact of an external standard is considerably weakened when members see it as a source of inappropriately directed pressure. Under such a condition, moreover, members are likely to use information other than that provided by the external standard in deciding upon the aspiration level for their group. One such source, we have seen, is the view most favored by groupmates. 
As in prior studies, it was found that members place their level of aspiration closer to a hard external standard than to an easy one, but the experimental procedures made it possible to ascertain, with a degree of certainty that could not be achieved in earlier research, that the closer similarity between a level of aspiration and a more difficult standard was largely due to the preference for attempting harder tasks, and not to the greater influence of the harder external standard.

These last findings indicate then that a group's reluctance to lower its goal, even though it has already failed to achieve that level, may not only develop because of restraints against lowering the goal but also because the members themselves view a harder goal as a potential source of greater satisfaction if they succeed (or of less dissatisfaction if they fail). One cannot conclude, however, that the greater willingness to conform to harder goals (observed in prior research) is always an artifact of the members' performances for harder aspirations. The procedures that were necessary in this investigation to create independence among variables also serve to limit the generality of the findings.

Each standard, whether high or low, was an isolated event and as such it may have had little logic in the eyes of the subjects, despite the experimenter's stated reason for the particular level given to the group. Each standard was chosen in relation to the prior level of aspiration set by the group and was not modified in the light of the group's performance; it is probable that a standard is seldom set elsewhere on such a basis. The effect of this close linkage between external standard and prior aspiration level, it is interesting to note, was that the external standards, whether hard or easy, gradually increased in difficulty simply because the subjects so increased their aspiration from trial to trial. (These harder standards are not unlike the annually increased demands made upon goal setters for a United Fund.) Each standard, moreover, had little implicit evaluation inherent in it. A low standard was not likely to be seen as derogatory in this experiment, whereas such a standard may often be taken as a comment on the potential ability of a group outside the laboratory. This point is worth noting because members in real life settings who give their group a low evaluation because its score is repeatedly worse than others, or who learn that observers expect their group to perform poorly, may become uncertain about what aspiration level to choose, harder or easier, and as a consequence, may be considerably more susceptible to pressures arising outside the group. Such a situation could not develop in the present study.

The individuals in the high DGS and low DGS conditions were distinctly different in their involvement and aspirations. Yet, in contrast to what we had been prepared to find, there was no evidence that members 
with more DGS were more susceptible to harder external standards in selecting aspirations for the group. Instead, participants in the high DGS groups were deeply involved in achieving a satisfying success and simply ignored external pressures when these were in a direction that opposed the attainment of such satisfaction.

The procedure used for creating central and peripheral positions was not at all effective-differences that have previously been found among the occupants of these separate roles did not appear here. The central person, moreover, did not perceive his role to be more important to the group than did the peripheral person, which was probably a correct view of his situation. The central person seemingly saw himself as an assistant to the experimenter and thus he consistently set his aspiration for the group close to the external standard provided by the experimenter regardless of whether it was a hard or an easy one.

\section{REFERENCES}

ForWard, J. Group achievement motivation and individual motives to achieve success and to avoid failure. Journal of Personality, 1969, 37, 297-309.

ForWARD, J., \& $Z_{A N D E R}, A$. Choice of unattainable group goals and effects on performance. Organizational Behavior and Human Performance, in press.

Menow, H., \& ZaNDER, A. Aspiration for group chosen by central and peripheral members. Journal of Personality and Social Psychology, 1965, 1, 224-228.

ZaAder, A., \& Medow, H. Individual and group levels of aspiration. Human Relations, 1963, 16, 89-105.

Zasder, A., Medow, H., \& Emron, R. Observers' expectations as determinants of group aspirations. Human Relations, 1965, 18, 273-287.

ZANDER, A., \& MEDow, H. Strength of group and desire for attainable group aspirations. Journal of Personality, 1965, 33, 122-139.

ZANDER, A., \& WulfF, D. Members' test-anxiety and competence: Determinants of a group's aspirations. Journal of Personality, 1966, 34, 55-70.

Zander, A., \& Newcomb, T. M., JR. Group levels of aspiration in United Fund campaigns. Journal of Personality and Social Psychology, 1967, 6, 157-162.

ZaAdER, A., \& ForWARD, J. Position in group, achievement motivation and group aspirations. Journal of Personality and Social Psychology, 1968, 8, 282-288.

Zander, A. Group aspirations. In D. Cartwright \& A. Zander (Eds.) Group dynamics research and theory. New York: Harper \& Row, 1968.

ZaNder, A., Forward, J., \& Albert, R. Adaptation of board members to repeated success or failure by their organizations. Organizational Behavior and Human Performance, 1969, 4, 56-76.

Zander, A. Motives and goals in groups. New York: Academic Press, 1971.

Recerved: May 24, 1970 